\title{
Balanced diet related knowledge, attitude and practices (KAP) among adolescent school girls in Noakhali district, Bangladesh: a cross sectional study
}

https://doi.org/10.1515/ijamh-2020-0106

Received May 7, 2020; accepted August 6, 2020;

published online September 2, 2020

\section{Abstract}

Objectives: Adolescence, a crucial period for growth velocity including sexual maturation, is an important period of life and young adolescent girls need to have proper knowledge, positive attitudes and practice of balanced diet to achieve optimum growth and development. Considering its importance this study attempts to assess the knowledge, attitude and practice (KAP) of balanced diets among adolescent schoolgirls in Noakhali district, Bangladesh.

Methods: A descriptive cross-sectional study was conducted in three secondary schools in Noakhali district, Bangladesh. A multistage sampling techniques was used to select schools and study participants. A total of 485 adolescent school girls participated and a pre-designed, validated and structured questionnaire was used for data collection. In addition to descriptive statistics, chi-square test and logistic regression were employed for analysis.

Results: The results from the study revealed that more than half of the students did not have good knowledge about a balanced diet, $42.8 \%$ had a positive attitude, whereas the practice of consuming a balanced diet was rather low (only

\footnotetext{
*Corresponding author: Susmita Ghosh, MS, Assistant Professor, Department of Food Technology and Nutrition science, Noakhali Science and Technology University, 3814 Noakhali, Bangladesh. Phone: +880 1521585539, E-mail: susmita.ftns@nstu.edu.bd. https://orcid.org/0000-0001-9771-8091

Md Ruhul Kabir, Mohammad Rahanur Alam, Akibul Islam Chowdhury and Md Abdullah Al Mamun, Department of Food Technology and Nutrition science, Noakhali Science and Technology University, Noakhali, Bangladesh, E-mail: ruhul109@gmail.com (M.R. Kabir), rahanuralam@gmail.com (M.R. Alam), akibul433@gmail.com (A.I. Chowdhury), mamun.nfs.du@gmail.com (M.A. Al Mamun). https://orcid.org/0000-0001-6801-9056 (M.R. Kabir). https:// orcid.org/0000-0001-8785-2705 (M.R. Alam). https://orcid.org/ 0000-0003-0741-046X (A.I. Chowdhury). https://orcid.org/00000002-0816-1808 (M.A. Al Mamun)
}

4.5\%). Students studying in government schools had better knowledge and attitudes than non-government school students. Moreover, $41.1 \%$ of students were underweight; more than $60 \%$ of respondent's mothers did not have an education higher than secondary school and were mostly unemployed housewives. Parent's education, mother's occupation, and types of school have a strong association with KAP; however, father's education and occupation showed an association of varying degrees. Being knowledgeable was related to positive attitudes, and students with good knowledge had (OR: 1.828; 95\% CI: 1.270-2.631) more likely to have positive attitudes towards a balanced diet.

Conclusions: Thus, proper knowledge about a balanced diet should be introduced with basic nutritional knowledge to all levels of public education. Interventions and programs can be designed to improve knowledge, attitude, and more specifically the practice at the household level so that adolescent girls can have a proper diet during their sexual maturation phase.

Keywords: anemia; attitude; balanced diet; Bangladesh; knowledge; practice.

\section{Introduction}

The word "Adolescence" comes from a Latin word "Adolescere" which means to mature, to grow, to emerge, or achieve an identity [1]. According to the World Health Organization (WHO), adolescents are those aged from 10 to 19 years [2]. Adolescence is a unique period of a girl's life as physical, cognitive, and psychological development occurs in this period [3]. Adolescence is a transition period from childhood to adulthood and characterized by rapid physical, biological, and hormonal changes resulting in psychosocial, behavioral, and sexual maturity in an individual. It is known as the second growth spurt of life, and both boys and girls undergo different experiences in this phase [4].

Physical and mental changes are experienced during adolescent periods, and that is why a balanced diet is vital 
during this period and due to a lack of maintaining a balanced diet, adolescent girls suffer different types of micronutrient deficiency, and iron is one of them is an essential mineral for adolescent girls as it has several biological functions in the body, including respiration, deoxyribonucleic acid (DNA) synthesis, cell proliferation, and energy production [5]. Nutrition and physical growth are integrally related; a balanced nutritional diet is a requisite for achieving full growth potential. Failure to consume an adequate diet at this time can result in delayed sexual maturation and can arrest or slow linear growth [6].

More than 1.8 billion adolescents live in the world, among which $89 \%$ live in middle-income and low-income countries [7]. In South Asia, the prevalence of undernutrition among adolescent girls is always in the same conditions as before due to a lack of proper knowledge and little attention in nutrition [8]. In Bangladesh, the rate of low body mass index (BMI) is about $50 \%$, and the rate of anemia $(\mathrm{Hb}<12 \mathrm{mg} / \mathrm{dl})$ among adolescent girls is about $25-$ $27 \%$ [9]. In Bangladesh, it is estimated that about $50 \%$ of adolescent girls intake lower energy than they needed, and there are several factors associated with it, such as- education level, socioeconomic status, income level, etc. [10]. Nutrition in adolescents can be satisfied by providing a healthy diet with more fibers [11].

It is estimated that half of the adult body weight and one-fifth of adult height is gained during this period [12]. The adolescent period is significant for girls for better future life, including- pregnancy and lactation. So, nutritional knowledge is required for a healthy lifestyle. Improving nutritional knowledge, attitude, and practices of adolescent girls will lead to more economic growth and healthier individuals [13].

Importance of behavioral studies was revealed by Waisbord [14] which applied to child survival programming. Behavior manifested in three forms, namely knowledge, attitudes, and practices [15]. Nutrition knowledge is essential for individuals to acquire a lifestyle that is healthy and free from disease [16]. Interventional studies which was carried out in Malaysia found that the knowledge, attitude, and practice of undergraduate students on healthy eating improved after intervention [17]. Improving the nutrition attitudes, knowledge, and practices of adolescents and youth is very important as it will lead to a more food-conscious society and healthier individuals [18].

This study was conducted to determine the level of knowledge, attitude, practice on a balanced diet, and its associations with different socioeconomic characteristics of the study population. Determining adolescent schoolgirls' knowledge, attitude, and practice of a balanced diet will provide concrete evidence, from where it is possible to generate a change mechanism to improve the situation.

\section{Methods}

\section{Study design}

This study was a descriptive cross-sectional study, and the target group of this study was school going adolescent girls from one of the sub-districts (upazila) of Noakhali district, Bangladesh selected randomly after clustering sub-districts to numbers; there are eight upazilas in this district. There are two government higher secondary and 43 non-government higher secondary schools in this district [19], and among those, one government and two non-government high schools were selected randomly. The sample size calculation was as follows [20]:

$$
n=N \div\left(1+N e^{2}\right)
$$

Here, $\mathrm{N}=$ Total school going adolescent girls in Sadar upazila, Noakhali region (20,451 girls) [19]; e=Level of significance (5\%).

The sample size calculation required 393 samples and adding a $10 \%$ non-response rate takes the total number to 433 ; however, finally, information from 485 students was taken. Distribution of students was as follows: 212 from Government Girls High School, 148 from Pourokalyan High School \& 125 from Banglabazar High School according to probability proportion to size.

Adolescent schoolgirls attending school at the study days were included and data were collected by face to face interview at the school premises. Students who didn't attend school while the study was conducted were left out from the study. Among the respondents, 31\% were subjected to measure hemoglobin levels to identify anemia status.

\section{Questionnaire}

A structured questionnaire was designed for conducting the survey, and it was standardized by a pilot study. In the questionnaire of this survey, there were 21 questions for balanced diet-related knowledge, 13 questions for attitude, and nine questions for practice was included.

\section{Scoring}

Score on balanced diet knowledge and practice ranged from 0 to 2. If they answer incorrectly and never practice a balanced diet, the score given is ' 0 '. If they answer correctly and always practice a balanced diet, the score given is ' 2 '. When they answer didn't know and practice sometimes, the score is ' 1 '. Attitude scores ranged from 0 to 4 . Score 4 is given for strongly agree, score 3 for agree, score 0 for don't know, score 2 for disagree and score 1 for strongly disagree, whereas negative questions were scored 4 for strongly disagree, score 3 for disagree, score 0 for don't know, score 2 for agree and score 1 for strongly agree [21]. 


\section{Assessment of anthropometry \& hemoglobin level}

The anthropometric data were collected by following the standard method. Height and weight were measured by stadiometer and electric weight machine, respectively. Hemoglobin levels of subjects were measured by using Hemocue Haemoglobinometer (Hb 201+).

\section{Statistical analysis}

All data were processed and analyzed by using SPSS software, version 23. Descriptive statistics were performed to determine the characteristics of the subject, balanced diet behaviors (knowledge, attitude, and practice), and also to determine the characteristics of the subject's parents. A Chi-square test was performed to assess the relationships between balanced diet behaviors (knowledge, attitude, and practice), socio-demographic status, and subject's nutritional status. Logistic regression was carried out to assess independent relationships between a balanced diet and other associated variables.

\section{Role of the funding source}

The funders of the study had no role in study design, data collection, data analysis, data interpretation, or writing of the report. The corresponding author had full access to all the data in the study and had final responsibility for the decision to submit for publication

\section{Results}

From the socio-demographic characteristics of the respondents' table (Table 1) indicates that the age of adolescent girls involved in this study was ranging from 13 to 17 years (Mean \pm SD:15.11 \pm 1.05 ). Among all the respondents, $44.1 \%$ of girls were from government schools and $55.9 \%$ of girls from non-government schools. More than one-third of the subject's parents had a low level of education. Most of the respondents' fathers were employed; however, mothers were mostly unemployed housewives.

The study found that about $41.2 \%$ of subjects were underweight, which indicated the low nutritional status of adolescent girls in our study area. Only $43.3 \%$ were normal, $12.0 \%$ were overweight, and $3.5 \%$ were obese (Table 1 ). It was also found that $47.4 \%$ were non-anemic and 80 subjects were suffered from anemia, among which $44.7 \%$ were mildly anemic, $7.2 \%$ were moderate anemic, and $0.7 \%$ were severely anemic. Analysis of knowledge, attitudes, and practices of a balanced diet by the study participants reveals that $45.6 \%$ of them had good knowledge, $42.7 \%$ of them had good attitudes towards a balanced diet; however, the practice of consuming a balanced diet was rather low (only 4.5\%).

Table 2 represents the association between sociodemographic characteristics and dietary behaviors, and the analysis found out the relation exists between types of
Table 1: Distribution of the respondents according to sociodemographic characteristics $(n=485)$.

\begin{tabular}{|c|c|c|}
\hline Items & Frequency $\mathbf{N}$ & Percent \% \\
\hline \multicolumn{3}{|l|}{ Religion of respondent } \\
\hline Muslim & 460 & 94.8 \\
\hline Hindu & 25 & 5.2 \\
\hline \multicolumn{3}{|l|}{ Type of school } \\
\hline Government & 214 & 44.1 \\
\hline MPO listed & 271 & 55.9 \\
\hline \multicolumn{3}{|l|}{ Education of respondent's father } \\
\hline Illiterate and can sign, read and write & 109 & 23.0 \\
\hline JSC and SSC & 129 & 27.2 \\
\hline HSC and higher study/others & 236 & 49.8 \\
\hline \multicolumn{3}{|l|}{ Education of respondent's mother } \\
\hline Illiterate and can sign, read and write & 120 & 24.9 \\
\hline JSC and SSC & 193 & 40.0 \\
\hline HSC and higher study/others & 169 & 35.1 \\
\hline \multicolumn{3}{|l|}{ Occupation of respondent's father } \\
\hline Employed & 454 & 93.6 \\
\hline Unemployed & 23 & 4.7 \\
\hline \multicolumn{3}{|l|}{ Occupation of respondent's mother } \\
\hline Employed & 53 & 11.1 \\
\hline Unemployed & 428 & 88.9 \\
\hline \multicolumn{3}{|l|}{ Nutritional status (BMI) } \\
\hline Underweight & 200.0 & 41.2 \\
\hline Normal & 210 & 43.3 \\
\hline Overweight & 58.0 & 12.0 \\
\hline Obese & 17.0 & 3.5 \\
\hline \multicolumn{3}{|l|}{ Anemia status $(n=145)$} \\
\hline Normal & 72.0 & 47.4 \\
\hline Mild anemic & 61.0 & 44.7 \\
\hline Moderate anemic & 11.0 & 7.2 \\
\hline Severe anemic & 1.0 & 0.7 \\
\hline
\end{tabular}

school, parents' education and occupation, and BMI with knowledge, attitudes towards a balanced diet; nevertheless, with practice, varying degree of relation was observed.

In the present study, it was found that there was a statistically significant relationship between student's knowledge, attitude, and BMI to type of school $(\mathrm{p}<0.05)$. While the relation between type of school and practice was not significant $(\mathrm{p}=0.262)$ (Table 2), it was also identified that the relationship between knowledge and attitude to parent's education was statistically significant (Table 2) in where there was no relation between balanced diet practices and father's education but had associations with mother's education.

The present study identified that the knowledge score among Noakhali Govt. Girls High School and Poura Kalyan High School were nearly (OR:1.06; 95\% CI:0.620-1.815) and (OR:0.65; 95\% CI:0.380-1.118) which was higher than the Bangla Bazar High School. While seeing the father's occupation, it was found that the balanced diet knowledge score was about (OR:1.322; 95\% CI:0.432-4.051) and 


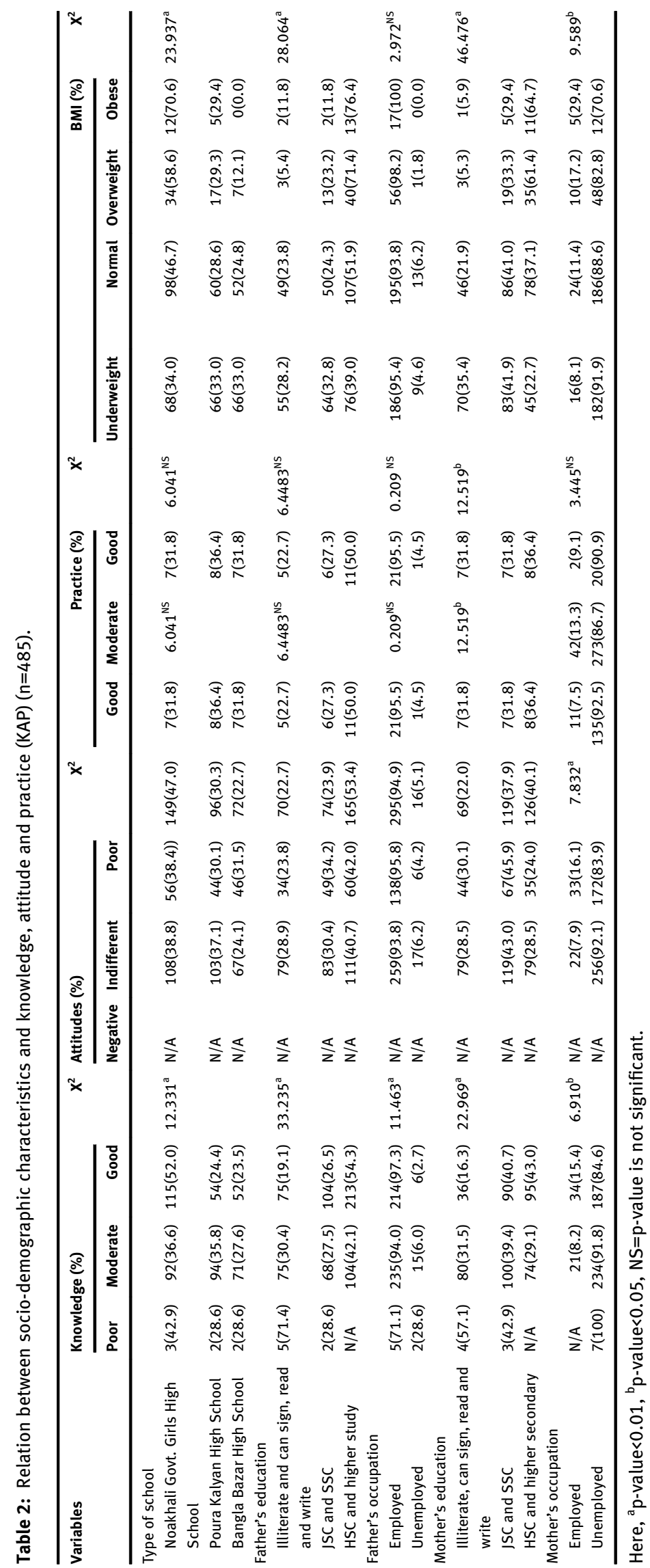


(OR:2.058; 95\% CI:0.748-5.659) which was higher in laborer and high employed fathers respectively than unemployed father. This table also describes that a mother's education was significantly associated with a knowledge score regarding a balanced diet $(\mathrm{p}<0.05)$. Those score on balanced diet was higher in those whose mothers were highly educated (Table 3 ).

The attitude score on a balanced diet was significantly correlated with the mother's education and types of school of adolescent girls from Noakhali Govt. Girls High School and Poura Kalyan High School had a higher positive attitude approximately (OR:0.614, 95\% CI:0.357-1.056) and (OR:0.38; 95\% CI:0.220-0.661) than Bangla Bazar High school. In the case of a mother's education, those respondents' mothers who had higher education had a positive attitude. It was also found that a highly educated mother's adolescent girl had (OR:1.090; 95\% CI:0.5102.331) higher positive attitude than illiterate and primarily educated mother's children (Table 3 ).

\section{Discussion}

This study was conducted in order to assess the dietary behavior of school-going adolescent girls in the Noakhali region. The nutritional status in terms of BMI of the girls was also seen in this study, and it was found that, the nutritional status of the study area girls not very good, which similar to another study conducted by Nurul et al. [9]. According to the balanced diet knowledge score, almost half the adolescents possessed good knowledge on a balanced diet, which is similar to the result of the study by Saibaba et al. [22] but did not corresponds with Parvin et al. [23].

In terms of the attitude towards a balanced diet, the result indicated that more than half of the adolescents had an indifferent attitude towards a balanced diet. Furthermore, there was a strong relationship between knowledge and attitude of adolescents on a balanced diet. In other studies, it was stated that only a few adolescent girls who had knowledge of a balanced diet had a better attitude and practice on a balanced diet [2, 3, 23]. Regarding the practice of a balanced diet among adolescent girls, it was found that only $4.5 \%$ of subjects have a good practice. Therefore, having good knowledge does not always ensure excellent practice. The study findings showed dissimilarity to result by Choi et al. [24].

In this study, it was found that there was a strong association between types of school and knowledge on a balanced diet. Government school-going adolescents had

Table 3: Association of KAP with different variables.

\begin{tabular}{|c|c|c|c|c|}
\hline \multirow[t]{2}{*}{ Variables } & Knowledge & Attitude & Practice & BMI \\
\hline & Odd ratio $(95 \% \mathrm{Cl})$ & Odd ratio $(95 \% \mathrm{Cl})$ & Odd ratio $(95 \% \mathrm{Cl})$ & Odd ratio $(95 \% \mathrm{Cl})$ \\
\hline \multicolumn{5}{|l|}{ Name of school } \\
\hline Noakhali Govt. Girls High school & $1.060(0.620-1.815)$ & $0.614(0.357-1.056)$ & & $1.060(0.629-1.785)$ \\
\hline Poura Kalyan High School & $0.652(0.380-1.118)$ & $0.381(0.220-0.661)^{\mathrm{a}}$ & & $0.827(0.494-1.383)$ \\
\hline Bangla Bazar High School & 1.0 & 1.0 & & 1.0 \\
\hline \multicolumn{5}{|l|}{ Father's education } \\
\hline Illiterate and primary education & 1.0 & 1.0 & & 1.0 \\
\hline Secondary education & $1.792(0.944-3.403)$ & $1.673(0.875-3.199)$ & & $0.646(0.355-1.176)$ \\
\hline Higher education & $2.044(0.997-4.188)$ & $3.140(1.542-6.391)^{\mathrm{a}}$ & & $0.756(0.393-1.455)$ \\
\hline \multicolumn{5}{|l|}{ Father's occupation } \\
\hline Laborer & $1.322(0.432-4.051)$ & & & \\
\hline High employed & $2.058(0.748-5.659)$ & & & \\
\hline Unemployed & 1.0 & & & \\
\hline \multicolumn{5}{|l|}{ Mother's education } \\
\hline Illiterate and primary education & 1.0 & 1.0 & 1.0 & 1.0 \\
\hline Secondary education & $1.207(0.655-2.223)$ & $0.928(0.495-1.738)$ & $0.608(0.208-1.777)$ & $1.521(0.840-2.753)$ \\
\hline Higher education & $1.189(0.562-2.512)$ & $1.090(0.510-2.331)$ & $0.802(0.283-2.275)$ & $1.630(0.786-3.384)$ \\
\hline \multicolumn{5}{|l|}{ Mother's occupation } \\
\hline Employed & $1.827(0.938-3.556)$ & $1.530(0.801-2.920)$ & & $0.773(0.409-1.461)$ \\
\hline Unemployed & 1.0 & 1.0 & & 1.0 \\
\hline \multicolumn{5}{|l|}{ Knowledge status } \\
\hline Inadequate knowledge & & 1.0 & & \\
\hline Adequate knowledge & & $1.828(1.270-2.631)^{\mathrm{a}}$ & & \\
\hline
\end{tabular}

${ }^{a}$ Confidence interval $95 \%$ at $5 \%$ level of significance $\left(p<0.05^{\star}\right)$. 
better knowledge compared to non-government schools, but the rate of over-nourished was higher in government schools than non-government schools. These findings contradict the result of Shaaban et al. [25], and according to this study, private schools had better knowledge, attitude, and practice than government schools, but this knowledge was not adequate for adolescents. It was also found that private schools have a slightly better knowledge of a balanced diet than government schools. However, both schools had inadequate knowledge of a balanced diet. Knowledge about the sources of protein, carbohydrates, fat, etc., was higher in private schools than in government schools adolescent [25]. The attitude score was much similar in both types of schools. Nevertheless, practice on a balanced diet did not depend on knowledge of a balanced diet ( $p>0.05)$. Private schools are not like non-government schools and that is why the result of this study was not similar to the previous study as the environment of the nongovernment school is quite different from a government school.

Paternal education and occupational status played a substantial impact on dietary behavior regarding a balanced diet. Maternal education was mostly associated with the knowledge of a balanced diet and BMI of girls. It was found that $43 \%$ of adolescents had good knowledge of a balanced diet whose mother was highly educated. On the contrary, obesity among adolescents was higher with the education of mothers, which is related to Choi et al. [24]. Father occupation did not have much effect on the balanced diet behavior among adolescent girls. However, knowledge of a balanced diet was significantly correlated with the father's occupation ( $\mathrm{p}<0.05)$. On the other hand, the mother's education associated mainly with the dietary behavior of adolescent girls except for practice. So, the dietary behavior of adolescent girls is directly associated with the type of school, socioeconomic status, parent's education, home, and social environment [26]. According to Faruk Ahmed, a highly educated parent's children have less susceptibility to being underweight, but they are prone to be overweight and obese. Furthermore, The consumption of protein-rich foods such as milk, meat, eggs, and fruits is higher among children with educated mothers [10]. Adolescent girls with proper nutrition knowledge have good dietary behavior. In this study, it is found that more than $50 \%$ of girls had a positive attitude who had good knowledge of a balanced diet, and 50\% of girls had a good practice on a balanced diet correlated with knowledge on a balanced diet.

Practice on a balanced diet is essential for physical and mental growth in future life. In this study, it was found that those who had moderate practice on a balanced diet, had normal BMI (52.9\%). Moreover, the prevalence of overnutrition was higher among poor and moderate practice on a balanced diet than good practice. Nutritional knowledge was significantly associated with dietary habits. Many studies concluded that poor attention on nutrition and knowledge leads to health problems in the future [27, 28]. According to this study, two-third of adolescents believed that food consumption should be lower during adolescence than adults.

Personal hygiene is a crucial factor, which is associated with anemia. There was less chance of being anemic who had good personal hygiene, which was found in this study. It was found that only $19.1 \%$ of adolescents had anemia, who had a good score in personal hygiene. However, there is no association between personal hygiene with anemia, which is opposite to the study by Monika et al. [29].

\section{Conclusion}

The study underscores balanced diet-related knowledge, attitude, and practice of high school students of three different schools and found even if there is knowledge and a positive attitude, the practice of having a balanced diet is meager. A big chunk of students was underweight, and their parent's education \& occupation had varying degrees of association with their knowledge, attitude and practice (KAP). Hence, proper target-oriented programs and interventions should be adopted at high school level, and the related socioeconomic factors should be addressed in order to achieve better health. Counseling can be done to increase the knowledge, attitude and practice on a balanced diet among adolescent girls. Several types of plan and awareness programs can be organized by government and non-government organizations to enrich the dietary behavior among adolescent girls.

Acknowledgment: Authors are thankful to all the girls, teachers and the authority of the schools for their cooperation and participation in the study, without them, the study would not have been possible.

Research funding: The study was funded by Research Cell, Noakhali Science and Technology University (NSTU/RC/ 20/B-81).

Author contributions: Susmita Ghosh and Md Ruhul Kabir have designed the study and contributed on data collection, analysis and interpretation and as well as in manuscript writing. Mohammad Rahanur Alam contributed on data collection and manuscript writing as 
well. Akibul Islam chowdhury has contributed on data collection, data analysis and as well as manuscript writing. Md Abdullah Al Mamun has critically reviewd the writing of the manuscript.

Conflict of interest: The authors declared no conflict of interest.

Ethical approval: The ethical approval was taken from the Ethics Board of Noakhali Science and Technology University.

\section{References}

1. Kamat S, Sengupta R. Nutrition intervention for improvement of knowledge on anaemia prevention among adolescent girls in Mumbai (16-19 years). Nutrition 2019;4:136-9.

2. Shahabuddin A, Talukder K, Talukder M-K, Hassan M, Seal A, Rahman Q, et al. Adolescent nutrition in a rural community in Bangladesh. Indian J Pediatr 2000;67:93-8.

3. Asim S, Kamran J, Gilani R, Ozair N, Inam H, Khan SA, et al. Assessment of dietary habits of adolescent in army public schools in chaklala garrison. Pak Armed Forces Med J 2019;69 (2 Suppl):S273-9. Available from: https://pafmj.org/index.php/ PAFMJ/article/view/2890.

4. Vir S, Sreenath KC, Bose V, Chauhan K, Mathur S, Menon S. National policies and strategic plans to tackle undernutrition in India: a review. 2014.

5. Camaschella C. Iron-deficiency anemia. N Engl J Med 2015;372: 1832-43.

6. Story $M$. Nutritional requirements during adolescence. Textbook of adolescent medicine. Philadelphia: WB Saunders; 1992:75-84 pp.

7. Gupta MD. The power of 1.8 billion: adolescents, youth and the transformation of the future. New York: United Nations Population Fund; 2014.

8. Shekar M, Heaver R, Lee YK. Repositioning nutrition as central to development: a strategy for large scale action. Washington, DC: World Bank Publications; 2006.

9. Alam N, Roy SK, Ahmed T, Ahmed AS. Nutritional status, dietary intake, and relevant knowledge of adolescent girls in rural Bangladesh. J Health Popul Nutr 2010;28:86.

10. Ahmed F, Zareen M, Khan MR, Banu CP, Haq MN, Jackson AA. Dietary pattern, nutrient intake and growth of adolescent school girls in urban Bangladesh. Publ Health Nutr 1998;1:83-92.

11. Badran IG. Knowledge, attitude and practice the three pillars of excellence and wisdom: a place in the medical profession. East Mediterr Health J 1995;1:8-16.

12. Rah JH, Christian P, Shamim AA, Arju UT, Labrique AB, Rashid M. Pregnancy and lactation hinder growth and nutritional status of adolescent girls in rural Bangladesh. J Nutr 2008; 138:1505-11.

13. Jalambo MO, Sharif R, Naser IA, Karim NA. Improvement in knowledge, attitude and practice of iron deficiency anaemia among iron-deficient female adolescents after nutritional educational intervention. Global J Health Sci 2017;9:15-23.

14. Waisbord S. Where do we go next? Behavioral and social change for child survival. J Health Commun 2014;19(1 Suppl):216-22.

15. Black RE, Alderman H, Bhutta ZA, Gillespie S, Haddad L, Horton S, et al. Maternal and child nutrition: building momentum for impact. Lancet 2013;382:372-5.

16. Roszanadia R, Norazmir M. Knowledge, attitude and practice on healthy eating among special needs boarding school students. Int J Dairy Sci 2011;6:278-86.

17. Aung PP, Foung CS, Azman KB, Ain N, Zulkifeli B, editors. Knowledge, attitude, and practice of healthy eating among the 1st and 2nd year students of universiti Malaysia sarawak (UNIMAS). In: International conference on nutrition and food sciences IPCBEE; 2012, Singapore: IACSIT Press; 2012;39:188-194.

18. Elhassan MR, Gamal HE, Mohammed G. Nutrition knowledge attitude and practices among students of Ahfad University for women. Indian J Sci Res 2013;4:25-34.

19. District Statistics 2011. STATISTICS, B.B.O. Ministry of Planning, Government of The People's Republic of Bangladesh; 2013.

20. Isip FBT. Encouraging the use of Slovin's Formula in computing sample sizes in DMS survey related projects. Available from: www.ehow.com/way_5475547_slovins-formula-samplingtechniques.html\#ixzz2usf4Xw4v.

21. Patimah S, Royani I, Mursaha A, Thaha AR. Knowledge, attitude and practice of balanced diet and correlation with hypochromic microcytic anemia among adolescent school girls in Maros district, South Sulawesi, Indonesia. Biomed Res 2016;27: 165-71.

22. Saibaba A, Mohan Ram M, Ramana Rao G, Uma Devi S. Nutritional status of adolescent girls of urban slums and the impact of IEC on their nutritional knowledge and practices. Indian J Community Med 2002;27:151-6.

23. Mirmiran P, Azadbakht L, Azizi F. Dietary behaviour of Tehranian adolescents does not accord with their nutritional knowledge. Publ Health Nutr 2007;10:897-901.

24. Choi ES, Shin NR, Jung El, Park HR, Lee HM, Song KH. A study on nutrition knowledge and dietary behavior of elementary school children in Seoul. Nutr Res Pract 2008;2:308-16.

25. Shaaban S, Nassar M, Abd Elhamid D, El-Batrawy S, Lasheen R. Nutritional knowledge and attitude of adolescent school girls living in Cairo. Res J Med Med Sci 2009;4:421-7.

26. Yperman AM, Vermeersch JA. Factors associated with children's food habits. J Nutr Educ 1979;11:72-6.

27. Harvey-Berino J, Hood V, Rourke J, Terrance T, Dorwaldt A, SeckerWalker R. Food preferences predict eating behavior of very young Mohawk children. J Am Diet Assoc 1997;97:750-3.

28. Sharma SV, Gernand AD, Day RS. Nutrition knowledge predicts eating behavior of all food groups except fruits and vegetables among adults in the Paso del Norte region: Qué Sabrosa Vida. J Nutr Educ Behav 2008;40:361-8.

29. Singh M, Rajoura OP, Honnakamble RA. Anemia-related knowledge, attitude, and practices in adolescent school girls of Delhi: a cross-sectional study. Int J Health Allied Sci 2019;8:144. 